\title{
A Rare Case of a Woman Presenting with Axillary Silicone Lymphadenopathy Accompanied by Extracapsular Siliconoma and Thickened Capsule after an Implant-based Augmentation Mammaplasty
}

\author{
Jae Hong Kim* \\ Korean Society of Breast Implant Research, The W Clinic, Seoul, Korea
}

*Corresponding author: Jae Hong Kim, Korean Society of Breast Implant Research, The W Clinic, 9F Kukdong B/D, 596 Gangnam-daero, Gangnam-gu, Seoul 06626, Korea, Tel: +82-2-517-7617; E-mail: stenka@hanmail.net

Received: 15 Apr, 2021 | Accepted: 23 Apr, 2021 | Published: 30 Apr, 2021

Citation: Kim JH (2021) A Rare Case of a Woman Presenting with Axillary Silicone Lymphadenopathy Accompanied by Extracapsular Siliconoma and Thickened Capsule After an Implant-based Augmentation Mammaplasty. J Surg Open Access 7(2): dx.doi.org/10.16966/2470-0991.236

Copyright: (c) $2021 \mathrm{Kim} \mathrm{JH}$. This is an open-access article distributed under the terms of the Creative Commons Attribution License, which permits unrestricted use, distribution, and reproduction in any medium, provided the original author and source are credited.

\begin{abstract}
According to a review of literatures, silicone-induced lymphadenopathy occurs in association with rupture or silicone leakage. It has been reported to cause inflammation, neuropathy or systemic disorder. It should therefore be detected both correctly and promptly. The author experienced a rare case of a 38-year-old woman presenting with axillary silicone lymphadenopathy due to rupture of a silicone gel-filled breast implant. The patient received primary augmentation mammaplasty using a breast implant at other hospital; the current case highlights the importance of an ultrasoundassisted diagnosis of silicone lymphadenopathy before reoperation in a patient with rupture.
\end{abstract}

Keywords: Breast implants; Ultrasonography; Rupture; Reoperation; Silicones; Lymphadenopathy

\section{Introduction}

The popularity of a silicone gel-filled breast implant in the field of aesthetic and reconstructive augmentation mammaplasty has been well described in the literature since the 1960s [1]. In 1992, however, it faced a moratorium by the US Food and Drug Administration (FDA) because of concerns for possible risks of developing connective tissue diseases [2]. In November 2006, the US FDA approved the clinical use of a silicone gel-filled breast implant for an implant-based augmentation mammaplasty on condition that it is used for women aged 22 years or older; it declared that there is a lack of evidence showing a causal relationship between a silicone gel-filled breast implant and connective tissue disease or malignancy $[3,4]$.

It is well known that an implant-based augmentation mammaplasty is currently one of the most popular plastic surgeries performed in the US; $85 \%$ of 299,715 patients receiving augmentation mammaplasty were found to receive a silicone gel-filled breast implant, as reported by the American Society of Plastic Surgeons (ASPS) in 2019 [5]. Nevertheless, the accurate rates of rupture of a silicone gel-filled breast implant remain unclear; their estimated values vary, ranging from $0.3 \%$ to $77 \%$ [6]. The correct diagnosis of rupture of a silicone gel-filled breast implant poses a challenge for surgeons because silent cases of rupture may also occur [7]. On the other hand, silicone leakage may also occur even in the absence of rupture; it remains confined to the breast or spreads to regional lymph nodes or distant organs where silicone triggers the onset of foreign body reactions [8-11]. According to a review of literatures, silicone-induced lymphadenopathy occurs in association with rupture or silicone leakage [12-19]. It has been reported to cause inflammation, neuropathy or systemic disorder $[12,19]$. It should therefore be detected both correctly and promptly.

The author experienced a rare case of a 38-year-old woman presenting with axillary silicone lymphadenopathy due to rupture of a silicone gel-filled breast implant. Here, the author reports this case with a review of literatures.

\section{Case Description}

In September 7, 2020, a 38-year-old woman visited The W Clinic in Seoul, Korea with a chief complaint of axillary pain and mass. On history taking, the patient had a 6-year-history of receiving primary augmentation mammaplasty at other hospital. But the patient had a rupture of the device in the right breast. Therefore, the patient received reoperation for replacement of the device with the BellaGel ${ }^{\circ}$ SmoothFine (HansBiomed Co. Ltd., Seoul, Korea) at another hospital in 2020. On physical examination, the patient had capsular contracture of the Baker grade II in the left breast and I in the right breast accompanied by palpable mass in the right axilla.

On the same day of visit (on postoperative month 3), the patient received breast ultrasound using the Aplio i600 (Canon Medical System, Otawara, Tochigi, Japan) system with a $7-18-\mathrm{MHz}$ linear 
transducer at my clinic. This confirmed that the patient had a round, smooth or micro textured device in the subpectoral pocket. But the patient presented with no complications, such as folding, upside-down rotation, other than minimal fluid collection in both medial periprosthetic spaces (Figure 1A). Of note, the patient partially had a thickened capsule $(0.6-0.7 \mathrm{~mm})$ in the lower area of the left breast (Figure 1B). Moreover, the patient had a single lesion of extracapsular siliconoma, measuring as $7 \mathrm{~mm}$, in the right breast (Figure 1C). Furthermore, the patient also had a concurrent presence of a silicone infiltration to the ipsilateral axillary lymph node at multiple sites (Figure 1D).

At a follow-up, on postoperative month 9, the patient was evaluated for possible changes in thickened capsule, the number of sites of silicone infiltration to the axillary lymph node and the size and scope of extracapsular siliconoma (Figures 2A-2C). Despite the discomfort, however, the patient had no notable changes; the patient was planned for a continuous follow-up. Lymph node excision would also be necessary if the patient complain of pain.

\section{Discussion and Conclusion}

By definition, silicone lymphadenopathy is referred to as involvement of silicone in a lymph node; it is a rare complication of augmentation mammaplasty using a silicone gel-filled breast implant $[15,17,20]$. This poses a diagnostic dilemma for surgeons. Malignancy may be initially considered, but its possibility should be ruled out in a patient with a lump in the neck or axilla who had a past history of receiving augmentation mammaplasty using a silicone gel-filled breast implant [21].

To date, two different mechanisms underlying the migration of silicone to the tissue have been proposed; these include rupture or erosion of a silicone-containing surface or continued leakage through an intact surface $[22,23]$. The migration of silicone to the tissue causes fibrosis and foreign body granulomatous reactions [24]. This may be followed by the transportation of silicone particles to regional lymph nodes via macrophages in the reticulo-endothelial system [25]. Consequently, foreign body reactions may cause local

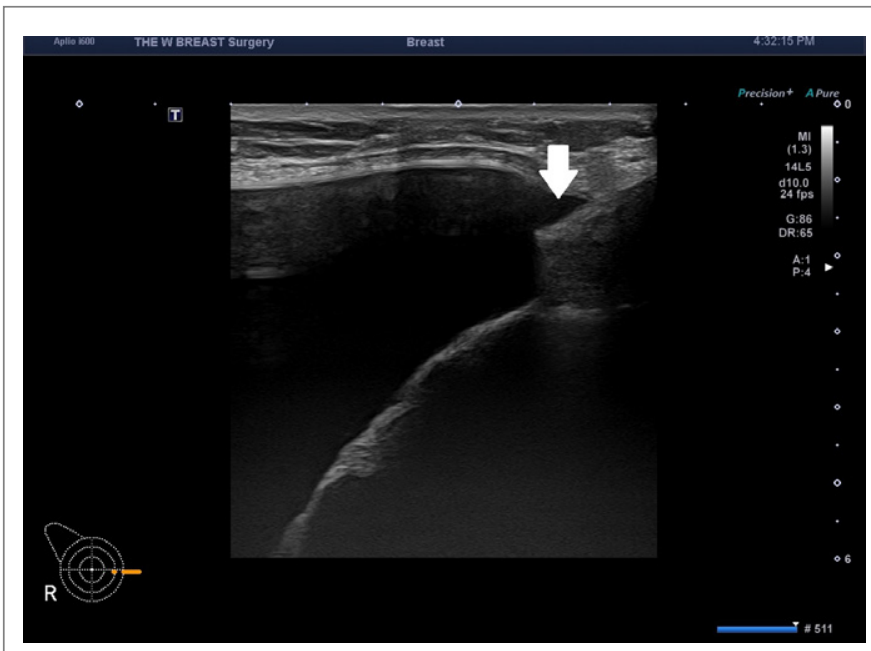

A

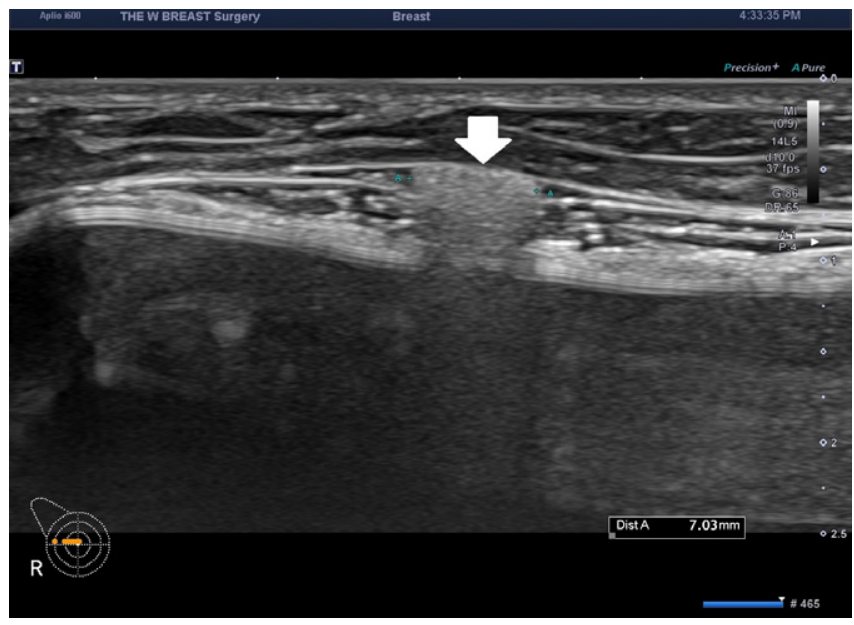

C

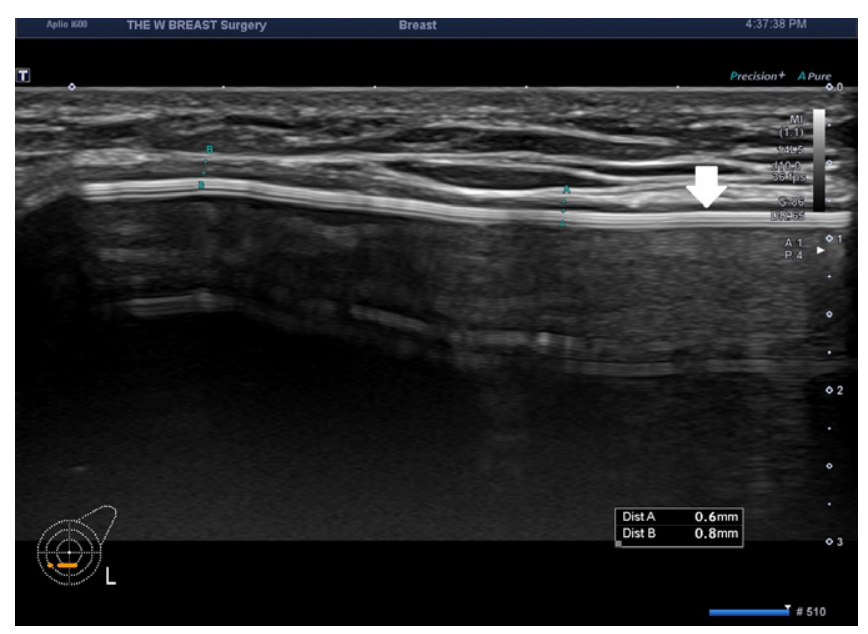

B

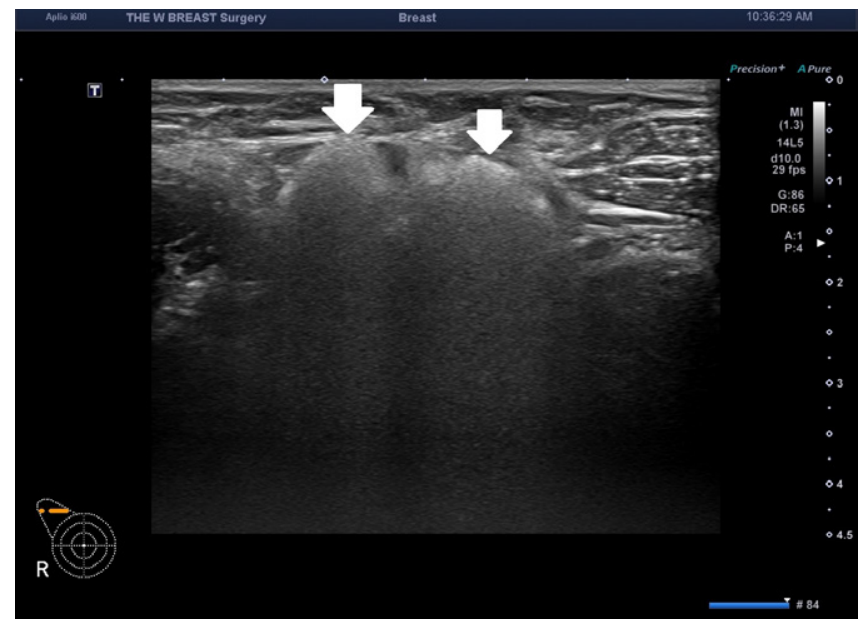

D

Figure 1: Sonographic findings on postoperative month 3.

(A) The patient presented with no complications other than minimal fluid collection in both medial periprosthetic spaces. (B) Moreover, the patient partially had a thickened capsule $(0.6-0.7 \mathrm{~mm}$ ) in the lower area of the left breast. (C) Moreover, the patient had a single lesion of extracapsular siliconoma, measuring as $7 \mathrm{~mm}$, in the right breast. (D) Furthermore, the patient also had a concurrent presence of a silicone infiltration to the ipsilateral axillary lymph node at multiple sites. 


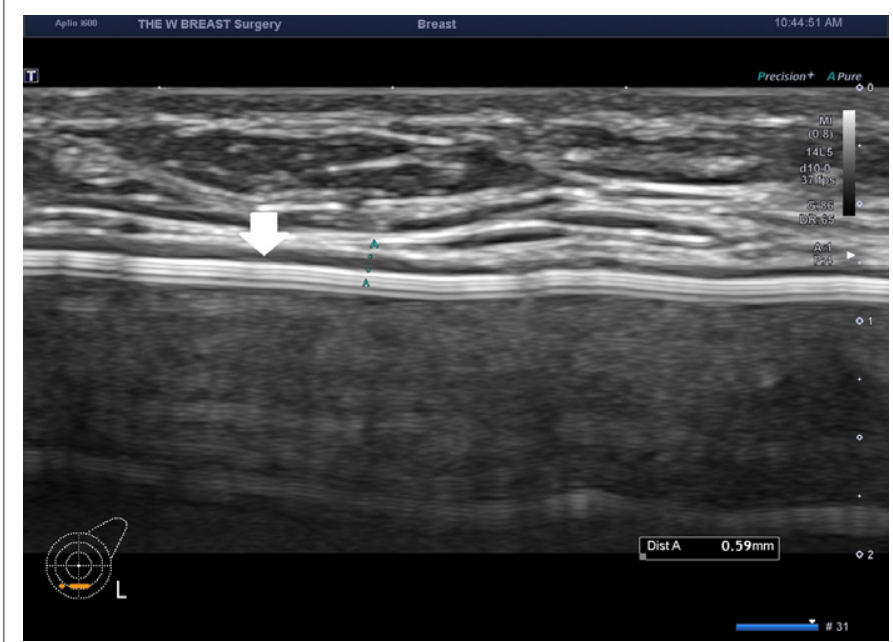

A

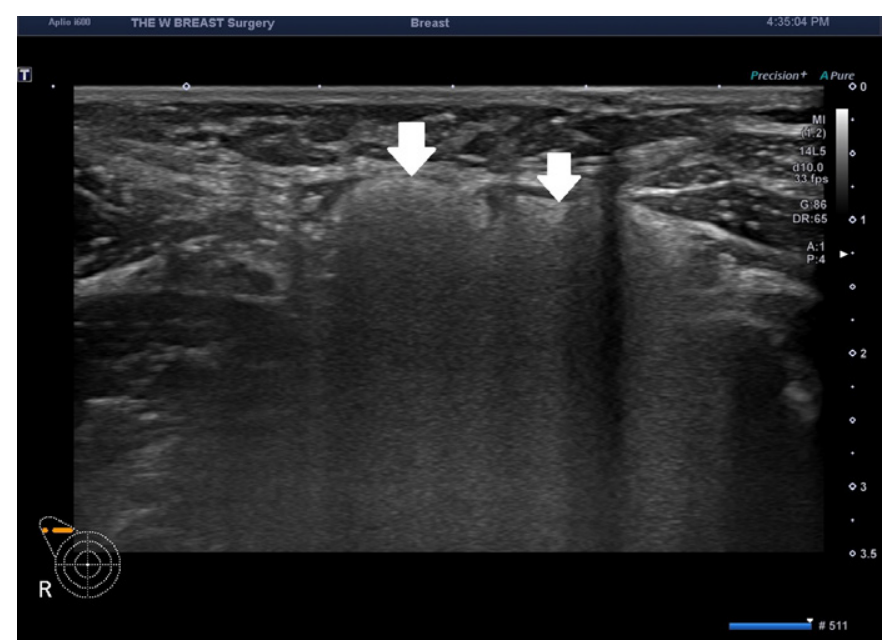

B

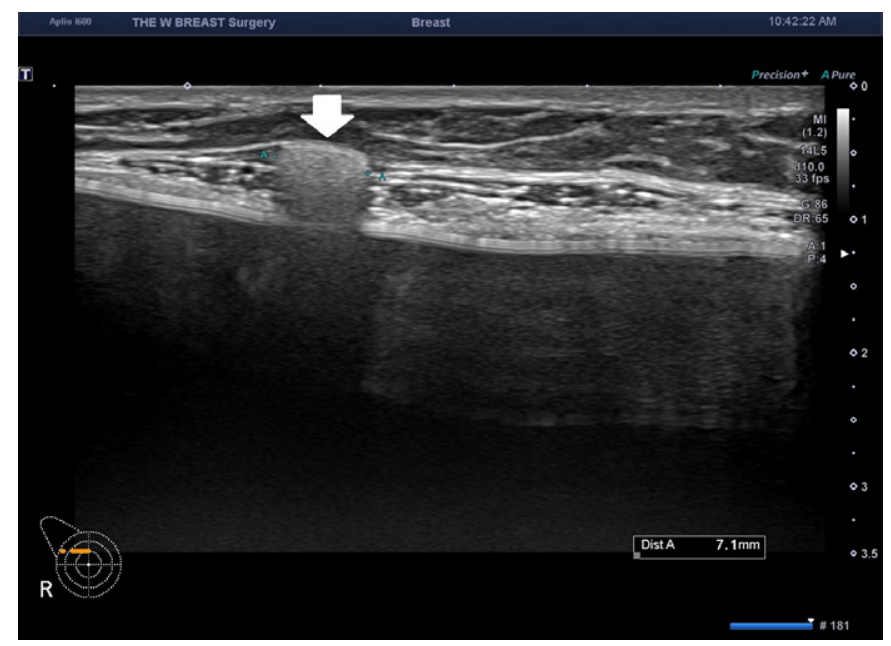

C

Figure 2: Sonographic findings on postoperative month 9.

The patient had no notable changes in (A) thickened capsule, (B) silicone infiltration to the axillary lymph node and (C) extracapsular siliconoma.

swelling of the involved lymph node. It has been documented that silicone lymphadenopathy primarily affects the axillary lymph node in a patient receiving augmentation mammaplasty using a silicone gelfilled breast implant $[22,26]$.

Thickened capsule is an abnormal condition whose thickness and scope vary, classified as total or partial cases, and it may correspond to capsular contracture of Baker grades II-IV. In the current case, the thickness of capsule in the left breast was measured as $0.6-0.7 \mathrm{~mm}$ on ultrasound, corresponding to capsular contracture of Baker grade II. This was a partial thickened capsule whose scope was confined to the lower breast. It did not undergo notable changes on postoperative months 3 and 9; it also did not progress to capsular contracture of Baker grade III. A meticulous monitoring of thickened capsule would be necessary if it is detected immediately after surgery. In other words, thickened capsule may serve as a predictor of capsular contracture.

The current case indicates the following: First, surgeon's management cannot be limited to a breast implant in a patient who was suspected of having or diagnosed with rupture of the device. They should examine the scope of rupture and the possible infiltration of silicone to the breast parenchyma or lymph nodes. Second, when surgeons intraoperatively confirm the presence of rupture, they are required to perform an ultrasound-assisted examination of the breast to check whether a patient's breast parenchyma is affected due to the extracapsular rupture or silicone is infiltrated into the lymph node. But this is not recommendable. Use of high-resolution ultrasound should be considered in examining whether there is a rupture of the device before reoperation, which should involve the lymph node and breast parenchyma as well as the device. Third, in a patient who preoperatively had siliconoma or silicone infiltration into the lymph node in association with extracapsular rupture, surgeons should obtain an informed consent from the patient for surgical excision or a monitoring of the clinical course depending on the size and number of lesions. Moreover, it would be mandatory to consider the possibility of lymphedema after an excision of the lymph node. Fourth, in a patient with an extensive presence of the extracapsular rupture, its scope cannot be intraoperatively determined and a complete excision of it 
cannot be achieved accordingly. This deserves an ultrasound-assisted examination at a follow-up for possible remnant of extracapsular siliconoma. Fifth, a patient with a single lesion of silicone lymphadenopathy is at a lower risk of developing lymphedema. In this patient, a complete excision of the lesion can be achieved. In addition, a follow-up can also be performed in a patient presenting with no notable symptoms. In a clinical setting, it may be difficult to identify the lymph node involving silicone. Lymphedema may also occur even after a complete excision of the lesion in a patient with infiltration of silicone in multiple lymph nodes. That is, surgeons should decide on a complete excision or a monitoring of the clinical course of the lesion based on symptoms, pain or palpable mass due to the infiltration of silicone into the lymph node. In a patient whose clinical course is monitored, surgeons should examine alterations in the number of sites of silicone lymphadenopathy and symptoms at a 6-month interval. This should be considered in revising or maintaining a treatment plan. Sixth, surgeons could not completely rule out the possibility of rupture in a patient for whom reoperation was planned for any reasons.

In the current case, the author decided to perform a follow-up considering that the patient had a single lesion of extracapsular siliconoma of $7 \mathrm{~mm}$ in size. In this regard, surgeons should actively apply high-resolution ultrasound to diagnosis of rupture of the device before reoperation. The author previously encountered even a patient whose lymph node was surgically removed under general anesthesia because of misdiagnosis as tuberculosis at a university hospital; the patient was finally diagnosed with foreign body reaction.

In conclusion, the current case highlights the importance of an ultrasound-assisted diagnosis of silicone lymphadenopathy before reoperation in a patient with rupture.

\section{Declaration}

The author has nothing to declare in relation to this manuscript.

\section{References}

1. Molitor M, Měšták O, Kalinová L, Krajcová A, Měšták J (2014) The history and safety of breast implants. Acta Chir Plast 56: 15-19.

2. Kessler DA (1992) The basis of the FDA's decision on breast implants. N Engl J Med 326: 1713-1715.

3. Tanne JH (2006) FDA approves silicone breast implants 14 years after their withdrawal. BMJ 333: 1139.

4. Rohrich RJ, Kaplan J, Dayan E (2019) Silicone implant illness: science versus myth? Plast Reconstr Surg 144: 98-109.

5. American Society of Plastic Surgeons (2019) Plastic Surgery Report: 1-25.

6. McLaughlin JK, Lipworth L, Murphy DK, Walker PS (2007) The safety of silicone gel-filled breast implants: a review of the epidemiologic evidence. Ann Plast Surg 59: 569-580.

7. Brown SL, Silverman BG, Berg WA (1997) Rupture of silicone-gel breast implants: causes, sequelae, and diagnosis. Lancet 350: 15311537.

8. Lahiri A, Waters R (2006) Locoregional silicone spread after high cohesive gel silicone implant rupture. J Plast Reconstr Aesthet Surg 59: 885-886.

9. Ikizceli T, Gülşen G, Akın I (2018) Silicone granuloma associated with pectoral muscle involvement after ruptured breast implant: a novel case report. Eur J Breast Health 14: 54-57.
10. Illman JE, Terra SB, Clapp AJ, Hunt KN, Fazzio RT, et al. (2018) Granulomatous diseases of the breast and axilla: radiological findings with pathological correlation. Insights Imaging 9: 59-71.

11. Moling O, Piccin A, Tauber M, Marinello P, Canova M, et al. (2016) Intravascular large B-cell lymphoma associated with silicone breast implant, HLA-DRB1*11:01, and HLA-DQB1*03:01 manifesting as macrophage activation syndrome and with severe neurological symptoms: a case report. J Med Case Rep 10: 254.

12. Bauer RP, Krajicek JB, Daniels EC, Shah SS, Ryu HJ (2011) Silicone breast implant-induced lymphadenopathy: 18 cases. Respir Med CME 4: 126-130.

13. Grubstein A, Cohen M, Steinmetz A, Cohen D (2011) Siliconomas mimicking cancer. Clin Imaging 35: 228-231.

14. Lykissa ED, Kala SV, Hurley JB, Lebovitz RM (1997) Release of low molecular weight silicones and platinum from silicone breast implants. Anal Chem 69: 4912-4916.

15. Zambacos GJ, Molnar C, Mandrekas AD (2013) Silicone lymphadenopathy after breast augmentation: case reports, review of the literature, and current thoughts. Aesthetic Plast Surg 37: 278289.

16. Truong LD, Cartwright J Jr, Goodman MD, Woznicki D (1988) Silicone lymphadenopathy associated with augmentation mammaplasty. Morphologic features of nine cases. Am J Surg Pathol 12: 484-491.

17. Dragoumis DM, Assimaki AS, Vrizas TI, Tsiftsoglou AP (2010) Axillary silicone lymphadenopathy secondary to augmentation mammaplasty. Indian J Plast Surg 43: 206-209.

18. Rivero MA, Schwartz DS, Mies C (1994) Silicone lymphadenopathy involving intramammary lymph nodes: a new complication of silicone mammaplasty. AJR Am J Roentgenol 162: 1089-1090.

19. Borghol K, Gallagher G, Skelly BL (2016) Silicone granuloma from ruptured breast implants as a cause of cervical lymphadenopathy. Ann R Coll Surg Engl 98: e118-e120.

20. Lee Y, Song SE, Yoon ES, Bae JW, Jung SP (2017) Extensive silicone lymphadenopathy after breast implant insertion mimicking malignant lymphadenopathy. Ann Surg Treat Res 93: 331-335.

21. Omakobia E, Porter G, Armstrong S, Denton K (2012) Silicone lymphadenopathy: an unexpected cause of neck lumps. J Laryngol Otol 126: 970-973.

22. Adams ST, Cox J, Rao GS (2009) Axillary silicone lymphadenopathy presenting with a lump and altered sensation in the breast: a case report. J Med Case Rep 3: 6442.

23. Hausner RJ, Schoen FJ, Mendez-Fernandez MA, Henly WS, Geis RC (1981) Migration of silicone gel to axillary lymph nodes after prosthetic mammoplasty. Arch Pathol Lab Med 105: 371-372.

24. van Diest PJ, Beekman WH, Hage JJ (1998) Pathology of silicone leakage from breast implants. J Clin Pathol 51: 493-497.

25. Tabatowski K, Elson CE, Johnston WW (1990) Silicone lymphadenopathy in a patient with a mammary prosthesis. Fine needle aspiration cytology, histology and analytical electron microscopy. Acta Cytol 34: 10-14.

26. Kulber DA, Mackenzie D, Steiner JH, Glassman H, Hopp D, et al. (1995) Monitoring the axilla in patients with silicone gel implants. Ann Plast Surg 35: 580-584. 